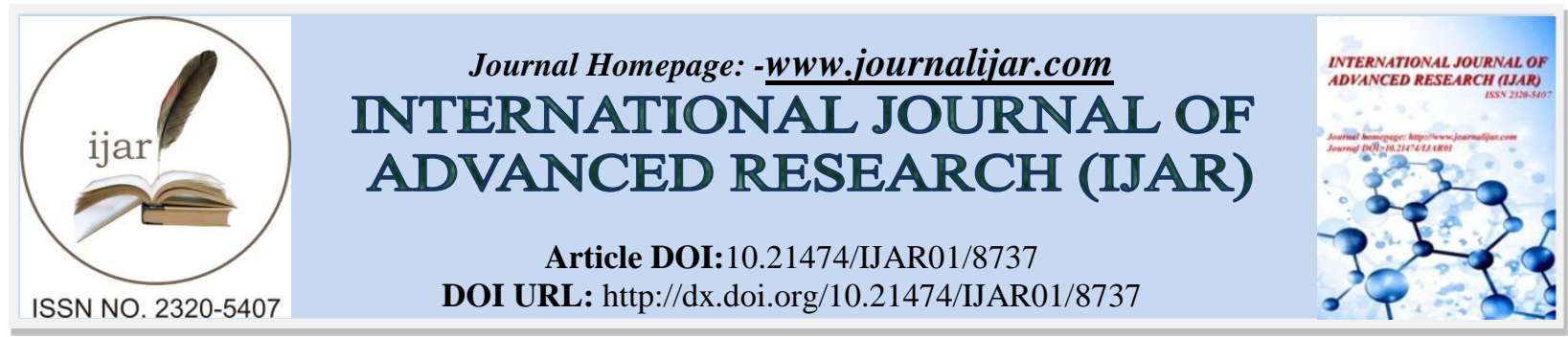

RESEARCH ARTICLE

\title{
LOBULATIONS OF THE FOETAL KIDNEY.
}

\author{
Dr. Sama Abdulkadar and Dr. Shameer VK. \\ Department of Anatomy, GMC Kozhikode.
}

\section{Manuscript Info}

\section{Manuscript History}

Received: 18 January 2019

Final Accepted: 20 February 2019

Published: March 2019

Key words:-

Behaviour, determinant, factor, health, seeking.

\begin{abstract}
Introduction: The knowledge of the lobulation pattern of foetal and adult kidneys is necessary for determining the normal anatomy of kidneys.

Aim: To study the foetal and adult kidneys for lobulations.

Method: 100 dissection specimens (70 adult, 30 foetuses) were studied at a tertiary center in northern Kerala.

Results: The surface of the foetal kidneys showed lobulations which were seen to reach the maximum number of 14 lobules by the $28^{\text {th }}$ week, after which the lobulations decreased in number to around 10-12 by term. The lobulations were clearly demarcated as belonging to the anterior or posterior surfaces by a longitudinal groove on the lateral margin of the kidney.The surfaces of the adult kidneys, on the other hand, were smooth except in a minority of cases, which showed lobulations. These lobulations on the surface of the adult kidney were more common on the anterior surface than on the posterior surface and when present on the posterior surface, they were more likely to be found closer to the lower pole.
\end{abstract}

Copy Right, IJAR, 2019,. All rights reserved.

\section{Introduction:-}

Lobulations, also termed as renal clefts are considered to be congenitally abnormal in adults by many authors (Last 1956) ${ }^{4}$; (Arid 1957) ${ }^{5}$. On the other hand lobulations in the foetal kidney are considered normal, with the number of lobulations at first increasing in number and then decreasing by the end of gestation. Most of the fetal lobulations disappeared during the first year of birth but varying degrees of lobulations may persist in the adult life (Williams PL 1995) ${ }^{7}$. Walsh PC $(2002)^{8}$ stated that most of the fetal lobulations disappeared during the first year of birth but varying degrees of lobulations may persist in the adult life and that it was not unusual to see a focal bulge in the mid lateral contour of the kidney, referred to as dromedary hump. He noted that it was a normal variation that occurred due to the downward pressure of the spleen on the left side.

In the present study an attempt has been made to study the lobulations present in foetal and adult kidneys.

\section{Materials and methods:-}

The material examined consisted of both foetal and adult kidneys. Of these, 70 were adult and 30 belonged to foetuses obtained from the Department of Anatomy, at a tertiary care center in North Kerala.. The youngest foetus in the series was of 16 weeks and the oldest was at term. The gestational age was calculated from the crown rump length. The psoas major muscle was identified in the formalin fixed foetuses and cadavers. Then the pelvis and 
ureter were found partly in front of and just medial to it. The ureter was divided at the upper and mid ureteric junction and the kidneys were removed. The shape, position of the hilum and surface lobulations of the kidneys were examined.

\section{Results:-}

Thirty foetuses, varying in age from 16 weeks to term were examined. The surface of foetal kidneys showed lobulations on both the anterior and posterior surfaces (Fig.1).
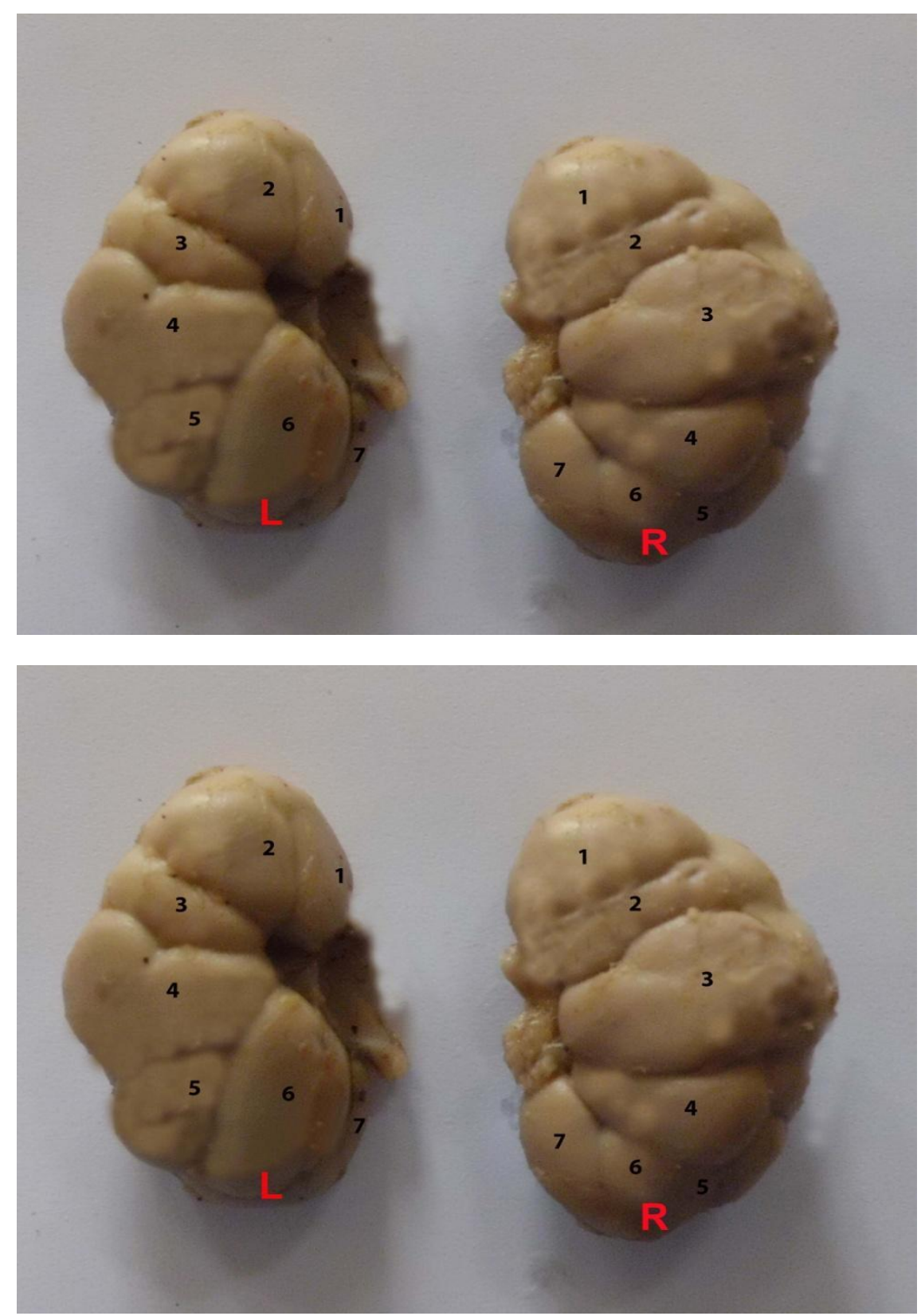

Fig 1:- Lobulations seen on a 28 week old foetus.

A: posterior surface; B: anterior surface; R: right kidney; L: left kidney 


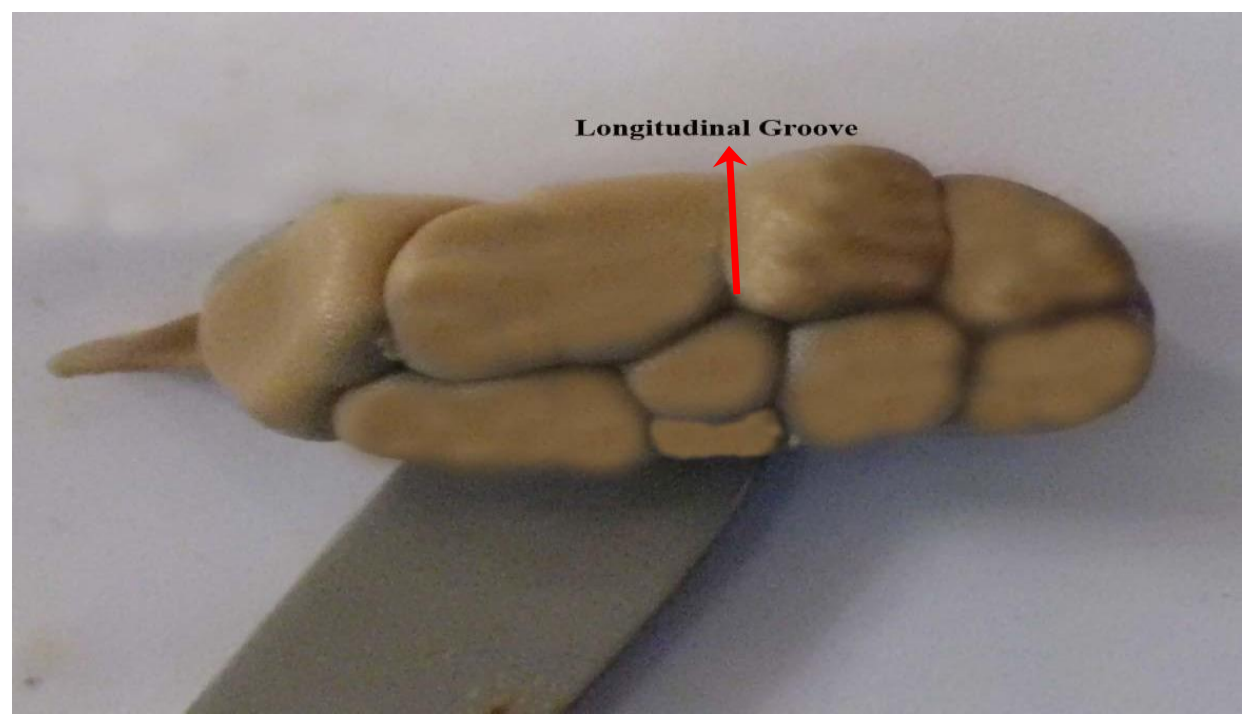

Fig 2:-

The kidneys of most of the foetuses showed a longitudinal groove on the lateral aspect (Fig.2) which demarcated the extent of the anterior and posterior lobulations.

The lobulations, also referred to as clefts, varied in shape, such as larger triangular, rectangular or polygonal lobules. In the present study, the lobules increased in number as well as definition with increasing age, reaching a maximum of 14 lobules by 28 weeks of age. Thereafter there was seen a decrease in the number, reaching around 10 at term. The number of lobules was equal in number on the anterior and posterior surfaces.

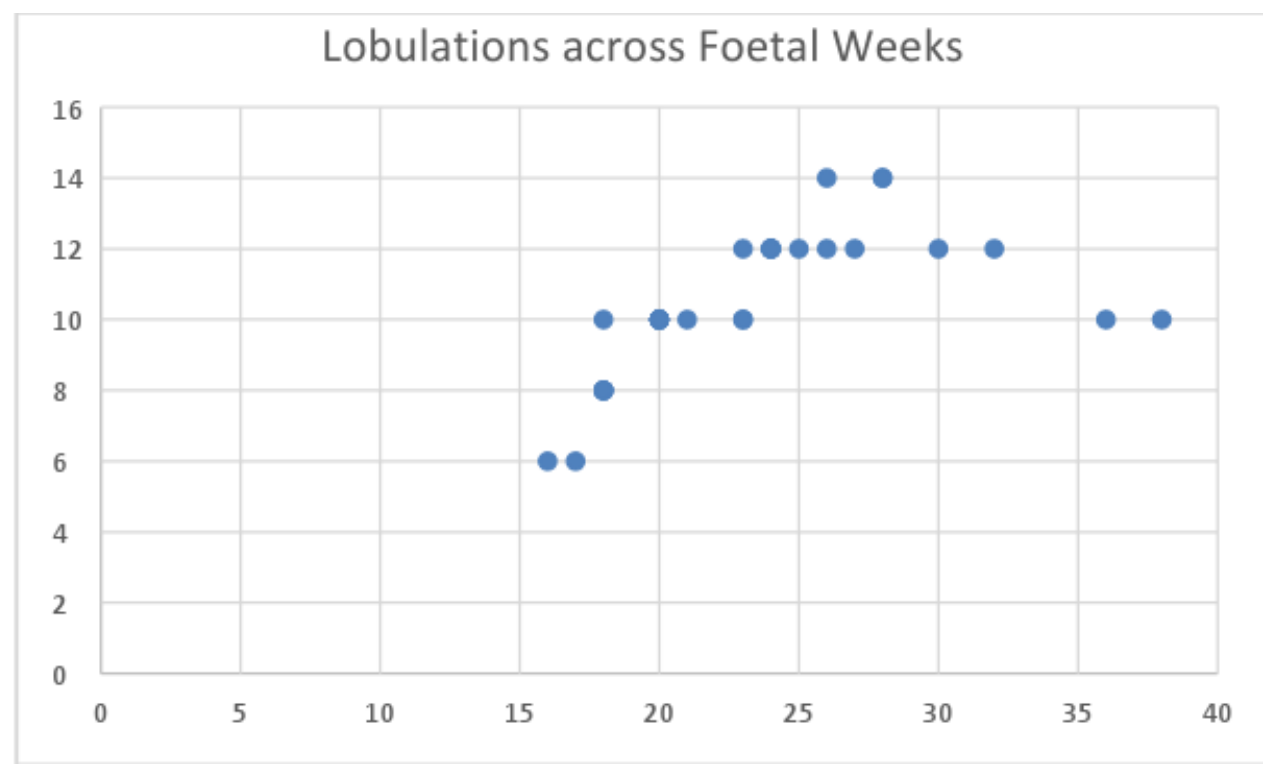

\section{Lobulation in adult kidneys:}

The surfaces of the majority of adult kidneys were found to be smooth with the exception of 10 kidneys which showed lobulations (Fig. 3). All kidneys showed lobulations on the anterior surface. In addition, 3 kidneys showed lobulations on the posterior surface as well. 
Table 1:-Lobulation in Adult kidneys

\begin{tabular}{|l|l|l|l|}
\hline Total No. & No. of Lobulations & Anterior surface & + Posterior surface \\
\hline 120 & $10(12 \%)$ & $10(12 \%)$ & 3 \\
\hline
\end{tabular}

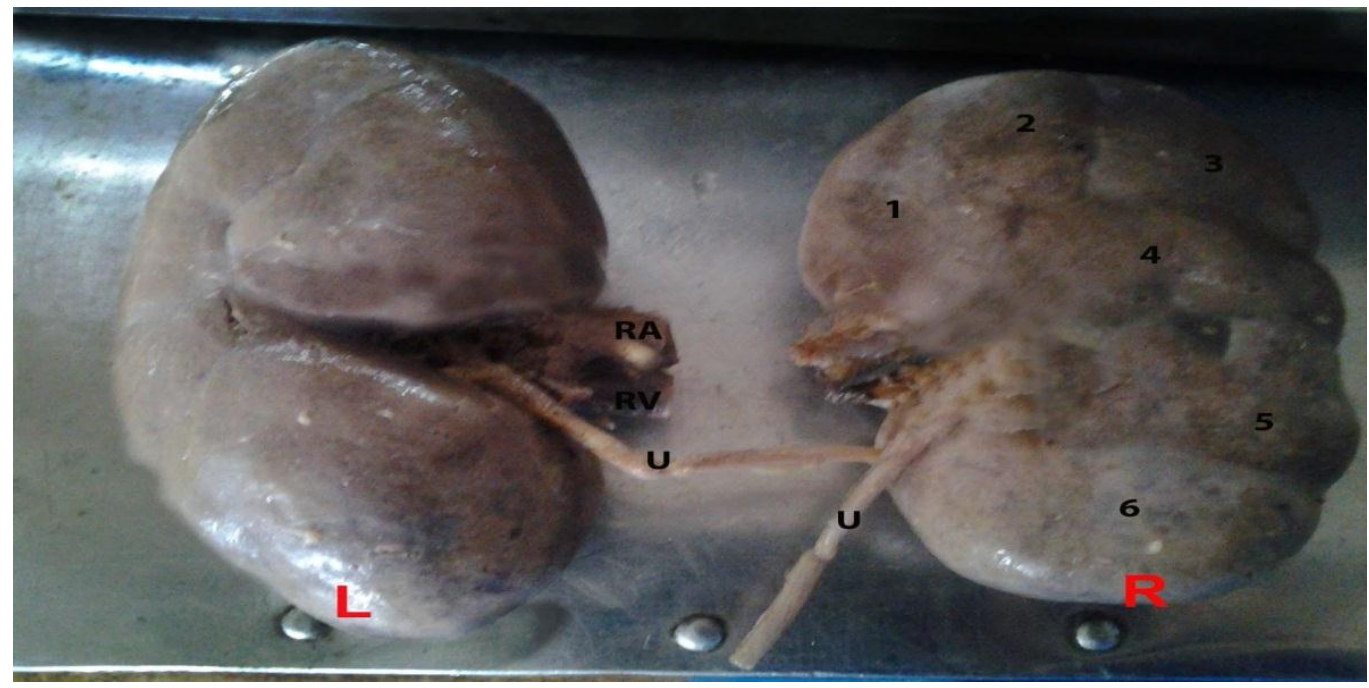

Fig 3:-Lobulations on adult kidney -posterior surface

L: left kidney; R: right kidney

Note the smooth posterior surface of the left kidney

The findings of lobulations of the foetal kidney varying with age and increasing in number to a maximum of 14 lobules by the $28^{\text {th }}$ week is similar to the findings reported by Sykes $(1963)^{1}$ and Ningthoujam DD et al $(2005)^{2}$. The lobulations were seen to increase in number in the present study, from the $16^{\text {th }}$ to $28^{\text {th }}$ weeks, thereafter the number was seen to decrease. But unlike Sykes ${ }^{1}$ (1963), the findings in the present study corroborated the findings of Ningthoujam $^{2}$ that the lobulations were less in number and less distinct at term.

The shape of the lobulations also varied and can be summarized as follows:

\begin{tabular}{|c|c|c|}
\hline Author (year) & No. of foetal kidneys studied & Shape \\
\hline Sykes $(1964)^{7}$ & 50 & Polygonal/ transverse clefts \\
\hline Ningthoujam et al $(2005)^{31}$ & 80 & polygonal, triangular, rectangular, mulberry \\
\hline Present study (2013) & 30 & polygonal, triangular, rectangular \\
\hline
\end{tabular}

Examination of the surface of the adult kidneys also showed the existence of lobulations but not as numerous as reported by Sykes ${ }^{1}$.

Table No 15:-Comparison of lobulated adult kidneys

\begin{tabular}{|l|l|l|}
\hline & Sykes (1964) & Present study (2013) \\
\hline Lobulated kidneys & $51 / 100$ & $10 / 120$ \\
\hline Anterior surface showing lobulations & $100 \%$ & $100 \%$ \\
\hline + Posterior surface showing lobulations & $20 \%$ & $30 \%$ \\
\hline
\end{tabular}

From the above table it is evident that the number of adult kidneys showing lobulations was far greater in Sykes ${ }^{1}$ study (51/100) as compared with the present study in which only 10 of the 120 adult kidneys showed lobulations. Foetal lobulations have been described by other authors but were considered uncommon (Davies 1958) ${ }^{3}$, or considered 'congenitally abnormal' (Last ${ }^{4}$ 1956, Arid ${ }^{5}$ 1957). Brodel (1901) ${ }^{6}$ stated that 'a novice may see a perfectly smooth kidney but an experienced eye may detect lobulations'. 
One feature common to the present study and the findings of Sykes ${ }^{1}$ was that the lobulations when present were seen invariably on the anterior surface. Those kidneys, which showed lobulations on the posterior surface in addition to lobulations on the anterior surface, showed the feature on the lower half than in the upper. Sykes ${ }^{1}$ explained these findings as a result of the movements of the diaphragm with the advent of respiration.

Thus, lobulations of the foetal kidney are the norm and while lobulations are usually absent in adult kidneys, they can be seen in a minority of specimens, usually on the anterior surface.

\section{References:-}

1. David Sykes. The morphology of renal lobulations and calyces, and their relationship to partial nephrectomy. Brit. J. Surg., 1964, Vol. 51, No. 4, April.

2. Ningthoujam DD, Chongtham RD \& Sinam SS; Pelvi-Calyceal System in Foetal and Adult Human Kidneys. J. Anat. Soc. India 54 (1) 1-11 (2005)

3. Davies, F., Gray's Anatomy, Descriptive and Applied. London: Longmans, Green. 1958. $32^{\text {nd }}$ ed., p1476

4. Cited by David Sykes. The morphology of renal lobulations and calyces, and their relationship to partial nephrectomy. Brit. J. Surg., 1964, Vol. 51, No. 4, April.

5. Last, R. J. Anatomy, regional and applied. London: Churchill. $1^{\text {st }}$ ed., 1956 pp. 351,352

6. Cited by David Sykes. The morphology of renal lobulations and calyces, and their relationship to partial nephrectomy. Brit. J. Surg., 1964, Vol. 51, No. 4, April.

7. Arid, I, companion in surgical studies, Edinburg: Livingstone., $2^{\text {nd }}$ ed, 1957, p. 1076. Cited by David Sykes. The morphology of renal lobulations and calyces, and their relationship to partial nephrectomy. Brit. J. Surg., 1964, Vol.. 51, No. 4, April.

8. Brodel, M., John Hopk. Hosp. Bull., 1901, 12,10. Cited by David Sykes. The morphology of renal lobulations and calyces, and their relationship to partial nephrectomy. Brit. J. Surg., 1964, Vol. 51, No. 4, April.

9. Williams PL, Bannister LH, Berry MM, Collins P, Dyson M, Dussek JE, Ferguson MWJ. Gray's Anatomy. 38th Ed., Edinburgh, Churchill Livingstone. 1995; 1815-1836.

10. Walsh PC, Retik AB, Vaughan ED Jr., Wein AJ, Kavoussi LR, Novick AC, Partin AW, Peters CA. Campbell's Urology. 8th Ed., 2002; Vol. 1; 20-21, 25-28; Vol. 3; 2007. 